\title{
Síndromes paraneoplásicos en tumores gastrointestinales. Revisión de tema
}

\section{A Review of Paraneoplastic Syndromes in Gastrointestinal Tumors}

\author{
Laura Rodríguez P. ${ }^{1}$, James Yurgaky S. ${ }^{2}$, William Otero R. ${ }^{3}$, Michel Faizal ${ }^{4}$
}

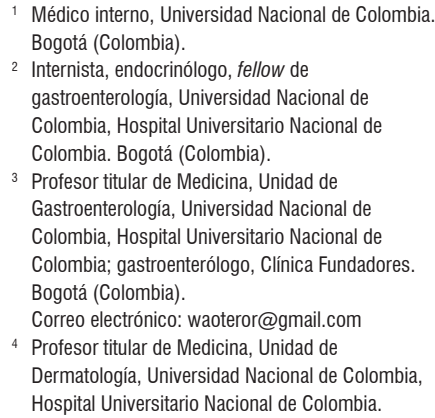

\begin{abstract}
Resumen
Los síndromes paraneoplásicos representan manifestaciones clínicas que producen los tumores en sitios distantes a ellos y que no están relacionadas físicamente con ellos ni con sus metástasis. Diferentes tumores gastrointestinales pueden presentar síndromes o manifestaciones sistémicas, dermatológicas, hematológicas, renales y neurológicas, entre otras. Aquí se ofrece una revisión de esas distintas manifestaciones.
\end{abstract}

Palabras clave

Síndrome paraneoplásico, gastrointestinal, tumores.

\section{Abstract}

Paraneoplastic syndromes produce tumors at sites distant from themselves and are not physically related to those tumors or to their metastases. Various gastrointestinal tumors may present syndromes or systemic, dermatological, hematological, renal, neurological and other manifestations. This study reviews these manifestations.

\section{Keywords}

Paraneoplastic syndrome, gastrointestinal, tumors.

\section{INTRODUCCIÓN}

Los síndromes paraneoplásicos (SPN) son un grupo heterogéneo de manifestaciones clínicas que se producen cuando un tumor provoca un daño en un órgano o sistema distante y que no están relacionadas físicamente con el tumor o sus metástasis (1). Esas alteraciones son independientes del efecto local del tumor, la invasión a otros órganos, los déficits nutricionales y las consecuencias derivadas del tratamiento antineoplásico $(1,2)$. La gran variedad de manifestaciones clínicas es secundaria a la liberación de sustancias por parte de las células neoplásicas malignas (2) que liberan hormonas, péptidos similares a hormonas, factores de crecimiento y citoquinas $(1,2,3)$. Adicionalmente, también participan respuestas inmunitarias que, inicialmente, estaban dirigidas contra las nuevas sustancias o antígenos tumorales (oncoantígenos) y que, por reacción cruzada, terminan lesionando tejidos normales $(3,4)$ y, finalmente, acumulando complejos inmunes (5). Los diferentes SPN se dividen según el órgano o sistema al que afecten y, clásicamente, se clasifican en endocrinometabólicos, dermatológicos, hematológicos, reumatológicos y neurológicos (3). En la presente revisión, se describen los SPN producidos por tumores gastrointestinales (GI). 


\section{CAQUEXIA ASOCIADA CON CÁNCER (CAC)}

Este es el SPN más frecuente y más conocido, que produce aumento de la morbimortalidad $(6,7)$ y consiste en la pérdida progresiva de masa muscular esquelética, con o sin pérdida de tejido adiposo $(6,7)$. El principal criterio para el diagnóstico es la pérdida involuntaria de peso, superior al $5 \%$ del peso usual, en los últimos 6 meses (7) (Figura 1). Se presenta en el $50 \%$ de todos los pacientes con cáncer $(6,8)$ y aumenta de manera progresiva conforme avanza la enfermedad $(6,9)$. En las últimas dos semanas de vida, se encuentra en más del $86 \%$ de los pacientes con cáncer (6). Es más frecuente en pacientes con adenocarcinoma gastrointestinal o pancreático $(7,10)$ y, en esos dos tipos de tumores, su incidencia es del $87 \%$ al $90 \%(7,10)$. Per se, produce la muerte en el $20 \%$ de los casos $(6,8,9,10)$. Su patogénesis es multifactorial, y las citoquinas inflamatorias inducidas o producidas por el tumor (tumorkines) desempeñan un papel fundamental (7). Entre esas citoquinas, se destacan el factor de necrosis tumoral alfa (TNF- $\alpha$ ), la IL-1, la IL-6 y el interferón $(6,7,8)$. Estas sustancias producen inflamación sistémica $(6,7,8,9,10)$, anorexia $(6,9,8,10$, $11,12)$, aumento del tejido adiposo pardo (9) y alteración del metabolismo de lípidos, proteínas y carbohidratos (8). Adicionalmente, producen un incremento del gasto energético (6). También se han encontrado otros mediadores, como la UCP3 (uncoupling protein) muscular, en humanos, y la IL-6, en modelos animales $(6,10)$.

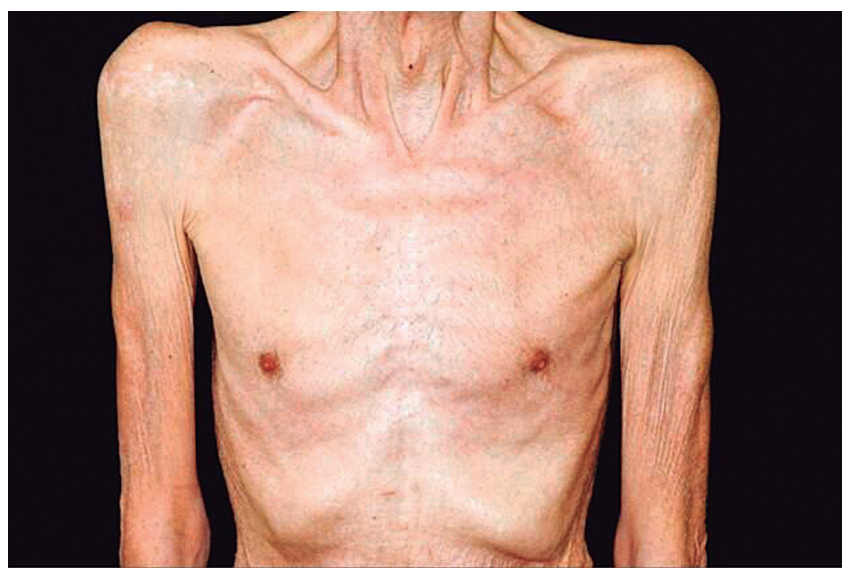

Figura 1. Caquexia. Tomado de: http://tomasalud.com/archivos/743

\section{SÍNDROMES PARANEOPLÁSICOS DERMATOLÓGICOS}

Representan el segundo tipo de síndrome paraneoplásico más frecuente después de los endocrinos (13). En los tumores GI, actúan como marcadores de dichos tumores $y$, en muchos casos, permiten detectar oportunamente esas neoplasias (14). Para configurar el síndrome, se deben cumplir los criterios de Curth: ausencia de infiltración directa de células malignas, inicio simultáneo y curso paralelo con el tumor y exclusión de síndromes genéticos (13, 15). Las alteraciones dermatológicas más importantes son las siguientes:

\section{Acantosis nigricans (AN)}

Consiste en la aparición de placas aterciopeladas con zonas hiperpigmentadas de relieve, simétricas, localizadas en sitios intertriginosos, como axilas, cuello y región anogenital, submamaria o mamilar $(14,15,16)$ (Figura 2). En algunos casos, se presentan proyecciones cutáneas pediculadas, llamadas acrocordones, y lesiones papilomatosas hipopigmentadas en las mucosas (17). En el $35 \%$ al $50 \%$ de los casos, se encuentra compromiso de la mucosa oral $(1,18)$, aunque también puede comprometer otras mucosas $(14,15)$ y, en el $41 \%$ de los casos, se asocia con prurito (19).

Su prevalencia es del 7\% al 74\% según la población (16). Esta alteración se clasifica en benigna, asociada con obesidad, sindrómica, maligna, acral, unilateral, inducida por medicamentos y mixta $(16,17)$. La forma maligna corresponde al $20 \%$ de los casos (20) y se presenta en 2 de cada 12000 pacientes con cáncer (21). A diferencia de la forma benigna, aparece generalmente en mayores de 40 años (13), sin asociación familiar (17), se inicia de manera espontánea, es extensa y progresa rápidamente $(14,15)$. Además, sigue un curso paralelo y es un indicador de recurrencia (17).

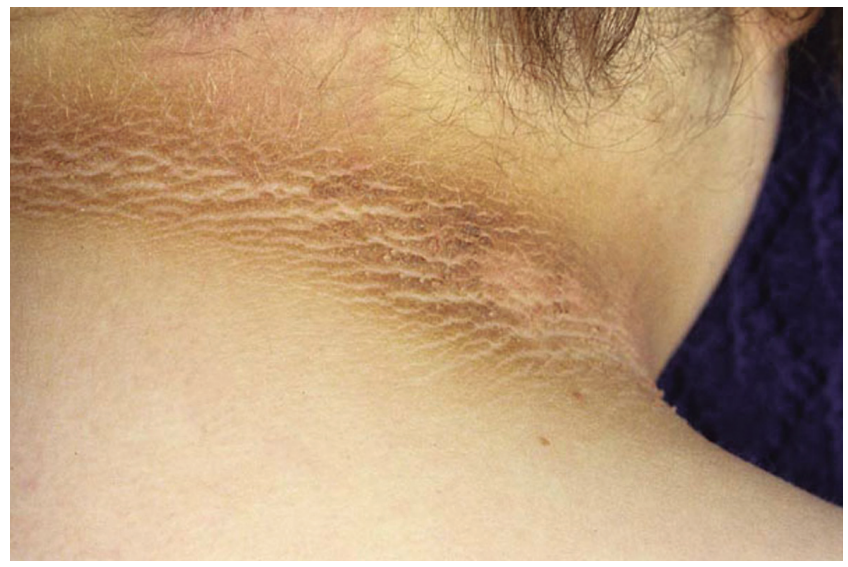

Figura 2. Acantosis nigricans. Tomado de: http://www.sanar.org/ cuidado-de-la-piel/acantosis-nigricans

El 90\% de los casos de AN maligna se asocian con neoplasias abdominales, que son gastrointestinales en el $70 \%$ al $90 \%$ de los pacientes $(13,22)$. El adenocarcinoma gástrico es el más frecuente, con una participación del 55\%-61\% (1, 13, 22), y del $73 \%$ en China (23). Las otras neoplasias que también se asocian con esa alteración son las del esófago, 
el páncreas, el hígado y la vía biliar (13). La alteración se detecta simultáneamente con el tumor en el $30 \%$ y el $60 \%$ de los casos, pero puede encontrarse antes de la neoplasia en el $17 \%$ y el $33 \%$ de los casos $(16,22)$. Por lo anterior, la detección de esta lesión amerita una profunda investigación, y más aún en pacientes mayores de 40 años con otro signo paraneoplásico, como la palma de intestino (Figura 3) y el signo de Leser-Trélat (Figura 4), sin una patología benigna que la pueda explicar, como la obesidad y otras endocrinopatías $(13,14,16,22)$.

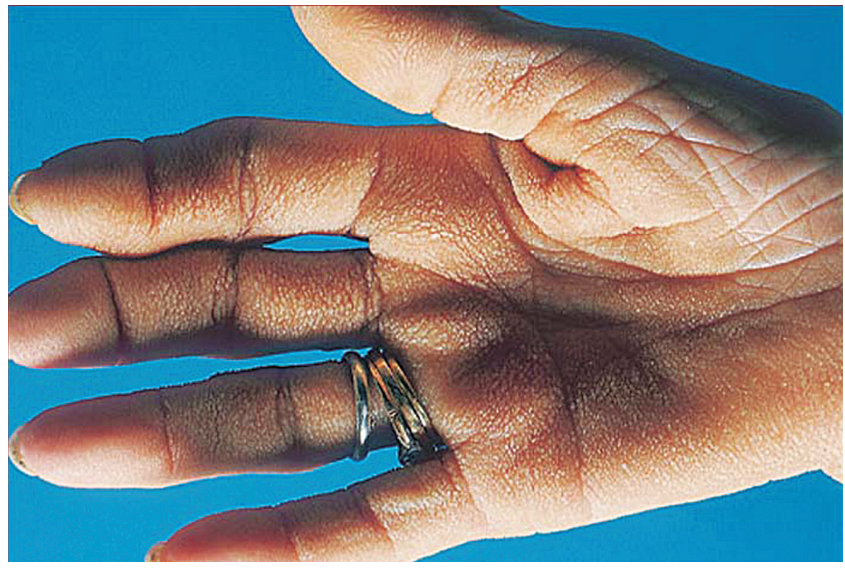

Figura 3. Palmas de intestino. Tomado de: http://www.handresearch. com/news/hands-on-cancer-hand-palm-cancers.htm

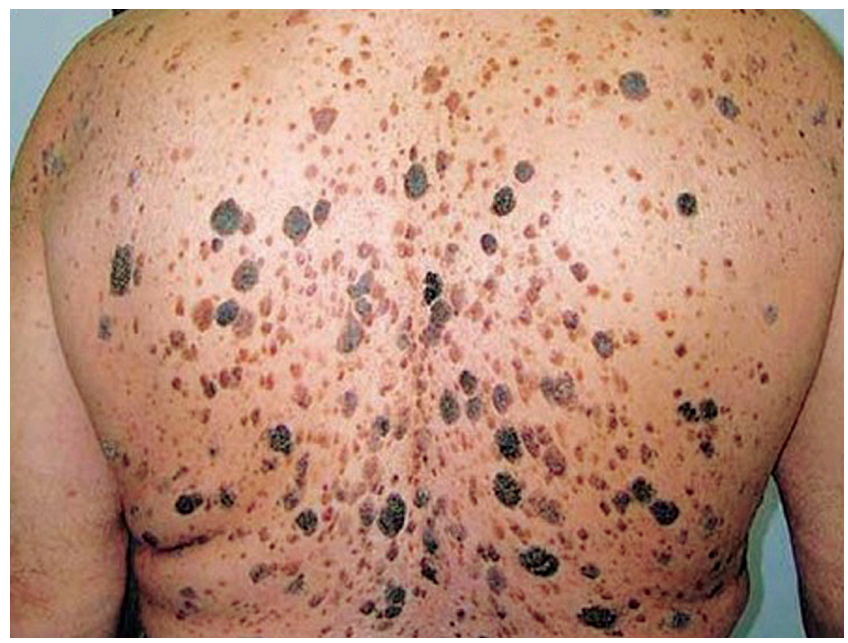

Figura 4. Signo de Leser-Trélat. Tomado de: https://quizlet. com/69755928/medi-tqs-flash-cards/

La acantosis nigricans, la queratodermia palmoplantar conocida también como "palmas de terciopelo o intestino" (tripe palms) y el signo de Leser-Trélat se han relacionado frecuentemente y, aunque su etiología se desconoce, se considera que tienen el mismo mecanismo fisiopatológico, como es la producción de factores de crecimiento por parte del tumor que interactúan con el factor de crecimiento epidérmico (EGF) o su receptor $(13,14,15,22)$. La palma de intestino consiste en un engrosamiento epidérmico rugoso en las palmas, con dermatoglifos prominentes (paquidermatoglifia) (15). Se asocia con malignidad en el $90 \%$ de los casos, y el tumor más frecuente es el adenocarcinoma gástrico (16). Puede tener inicio simultaneo (80\%), preceder (12\%) o aparecer después del desarrollo del tumor (8\%) (23).

El signo de Leser-Trélat es la aparición súbita o el aumento del tamaño o el número de múltiples queratosis seborreicas (24). Cuando se asocia con malignidad, se conoce como síndrome de Leser-Trélat (24). Sin embargo, en las personas de edad avanzada, es un hallazgo frecuente y, por lo tanto, en ellos la asociación con tumores es controvertida (15). Además, los tumores gastrointestinales también aumentan con la edad y podrían ser alteraciones independientes que coinciden en esos grupos etáreos (15). En las personas jóvenes, no se discute que tengan asociación causal y que sea un verdadero síndrome paraneoplásico (13). El tumor más frecuente es el adenocarcinoma gástrico (45\%) (25). Otros tumores asociados son los de colon y recto (13). Es inusual en los tumores de esófago, duodeno, páncreas, vesícula e hígado, así como también en otras neoplasias extradigestivas, como las de pulmón, próstata, vejiga, riñón, ovario, melanoma y neoplasias linfoproliferativas $(13,14)$. Cuando está presente, el tumor tiene un peor pronóstico (15). En el $26 \%$ al $51 \%$ de los pacientes con este síndrome, hay prurito $(19,26)$.

\section{Acroqueratosis paraneoplásica 0 síndrome de Bazex (Figura 5)}

Es una rara dermatosis psoriasiforme acral simétrica en la que las lesiones son violáceas y descamativas, con bordes definidos que comprometen la superficie nasal y malar, las manos, los pies, las orejas $(1,13,15,27)$ y la región ungueal (paroniquia, onicorrexis y onicolisis) (17). Se diferencia de la psoriasis en que las localizaciones de las lesiones son diferentes (17). El síndrome de Bazex se divide en 3 estadios clínicos: en el primero, la neoplasia es asintomática, y las lesiones solo afectan las regiones más distales; en el segundo, la neoplasia tiene síntomas locales, y las lesiones se prolongan; $y$, en el tercero, se presenta en neoplasias avanzadas en las que las lesiones pueden comprometer el tronco (17). Se asocia con malignidad en todos los casos descritos (27). En el $80 \%$ de los casos, los tumores subyacentes son carcinomas escamocelulares del tubo aéreodigestivo superior y pulmonar $(1,13,15,27)$, con la siguiente distribución: orofaringe y laringe (48\%), pulmón (17\%), esófago (10\%) y localización desconocida (16\%) (13, 14). Además, se ha relacionado con otros tumores, como adenocarcinoma gástrico, cáncer de colon y cáncer hepa- 
tobiliar (14). Es más frecuente en hombres mayores de 40 años (14) y, ocasionalmente, cursa con prurito (18\%) (28). Aunque se relaciona con mal pronóstico (27), se ha encontrado que puede preceder al tumor en el $65 \%$ de los casos, con una mediana de un año $(13,29,30)$. Con el tratamiento del tumor, esta lesión mejora en el 90\%-95\% de los casos y puede reaparecer si el tumor recurre; en ese caso, es un marcador de recidiva maligna (15).

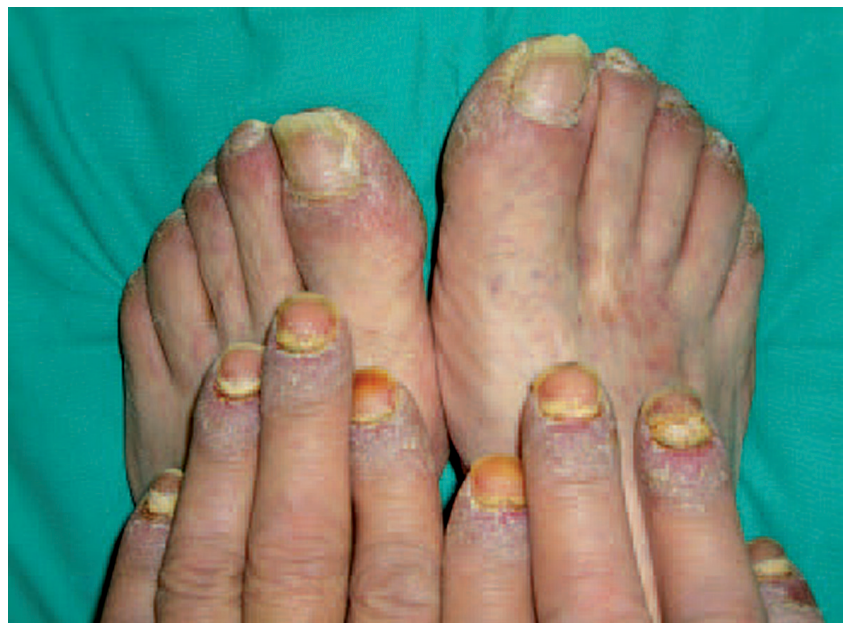

Figura 5. Acroqueratosis paraneoplásica o síndrome de Bazex. Tomado de: http://apps.elsevier.es/watermark/ctl_servlet?_f=10\&pident_ articulo $=13136503 \&$ pident_usuario $=0 \&$ pcontactid $=\&$ pident_revista $=103 \&$ ty $=112 \&$ accion $=$ L\&origen $=$ zonadelectura\&we $b=w w w . e l s e v i e r$. es\&lan $=$ es \&fichero $=103 v 100$ n04a13136503pdf001.pdf

\section{Hipertricosis lanuginosa paraneoplásica}

Consiste en la aparición de vello fino y largo no pigmentado, de rápido desarrollo y de predominio en rostro (13) (Figura 6). Se considera que es secundario a citoquinas o a factores de crecimiento secretados por el tumor, los cuales estimulan los folículos pilosos $(13,14)$, y es más frecuente en las mujeres (14). El principal tumor digestivo subyacente es el de colon y recto, superado solo por el carcinoma pulmonar $(31,32)$. Precede el diagnóstico hasta en dos años y medio (13). Cuando se hace el diagnóstico, usualmente el tumor ya es metastásico, por lo cual se considera un síndrome que indica un pronóstico pobre (14). Puede coexistir con AN maligna (14) y con CAC (13). Otros tumores que la originan son el cáncer de páncreas, de vesícula biliar y de mama $(13,32)$.

\section{Pénfigo paraneoplásico (Figura 7)}

Es una enfermedad ampollosa acantolítica mucocutánea (15). La forma paraneoplásica compromete principalmente las mucosas y afecta los ojos, con conjuntivitis pseudomembranosa, en el 70\% de los casos (18). Involucra tronco, miembros, palmas, plantas, mucosa oral, esófago y genitales $(14,15)$. Se cree que es el resultado de un mecanismo de reacción cruzada de anticuerpos contra desmosomas y hemidesmosomas (33). En un tercio de los pacientes, no hay una neoplasia conocida (33), y la mayoría ocurre en casos de malignidad hematológica (84\%). Sin embargo, en el 10\%, se asocia con adenocarcinoma de colon y páncreas $(15,18)$.

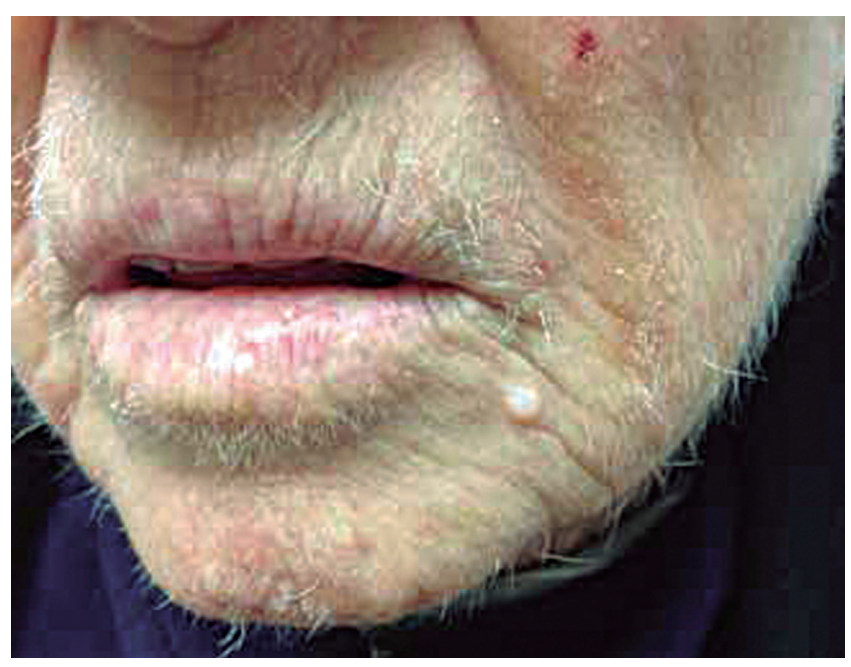

Figura 6. Hipertricosis lanuginosa paraneoplásica. Tomado de: http:// www.medigraphic.com/pdfs/cosmetica/dcm-2015/dcm153f.pdf

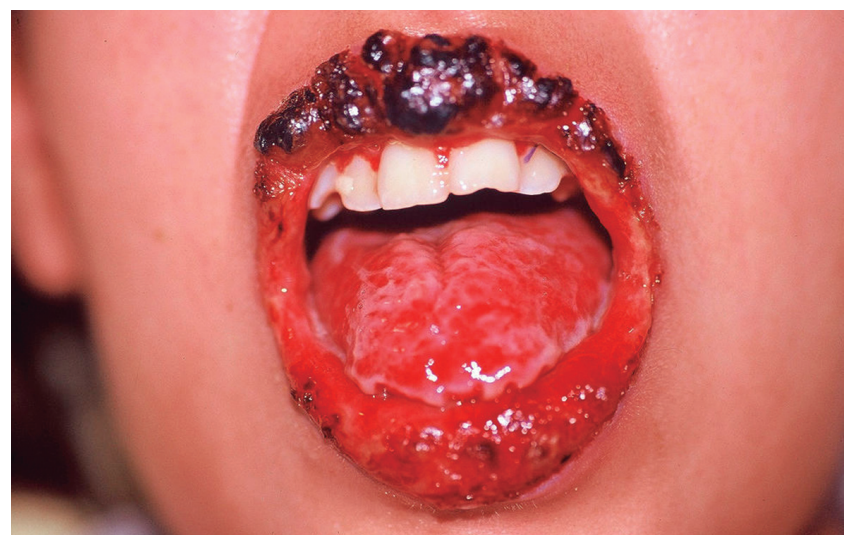

Figura 7. Pénfigo paraneoplásico. Tomado de: http://actasdermo. org/es/pnfigo-paraneoplsico-sndrome-multiorgnico-autoinmuneparaneoplsico-/articulo/S0001731010003339/

\section{Dermatomiositis paraneoplásica}

Es similar a la dermatomiositis (DMM) clásica, una miopatía inflamatoria idiopática, con incidencia de 5 a 10 casos por cada 100000 habitantes (34). Cuando aparece en personas mayores de 40 años, se asocia con neoplasias malignas, incluidas las gastrointestinales, en el $15 \%-40 \%$ de los casos $(15,35)$. Clínicamente, hay debilidad muscular proximal, rash en heliotropo periorbital, pápulas de 
Gottron localizadas en nudillos y articulaciones interfalángicas de coloración eritematosa a violácea, y signo de chal o capelina, representado por áreas violáceas con telangiectacias - llamadas "poiquilodermia" - en zonas de exposición solar, además de hiperqueratosis en palmas $(14,17)$. Asimismo, pueden encontrarse alteraciones en las uñas, como engrosamiento de la cutícula, telangiectacias en pliegues ungeales (17) y disfagia en el 10\%-20\% de los pacientes (34). Los criterios diagnósticos incluyen alteraciones cutáneas, musculares, de la electromiografía, de la biopsia muscular y de las enzimas musculares (17). En la Figura 8, se observa una paciente con eritema violáceo simétrico en los párpados superiores, conocido como rash en heliotropo, además de eritema facial y signo de chal o capelina, representado por eritema violáceo en la región superior del tórax y los brazos.

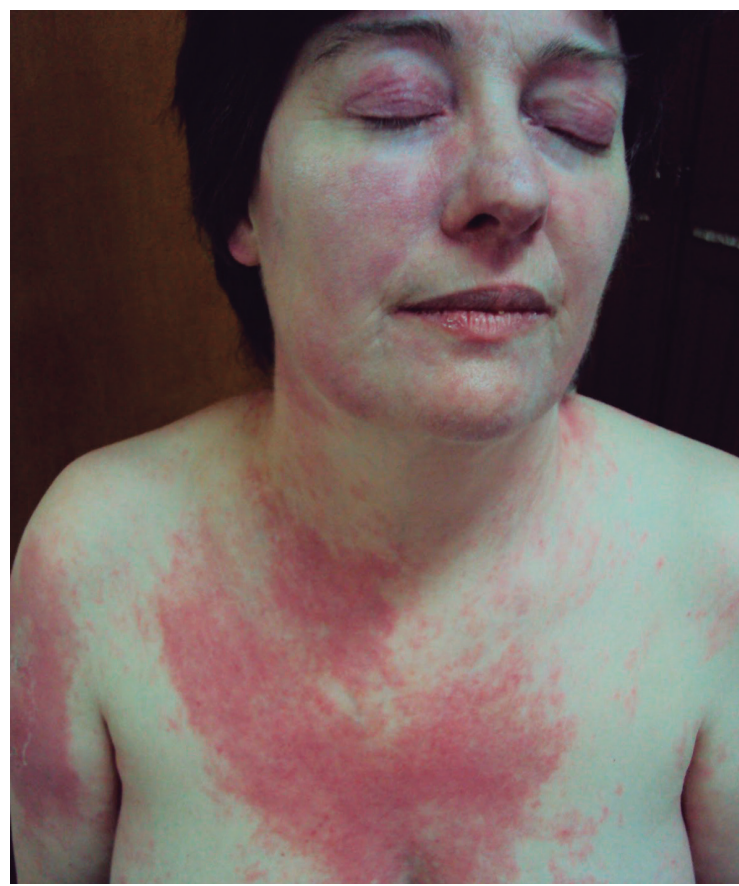

Figura 8. Dermatomiositis. Tomado de: http://www.elrincondelamedicinainterna.com/2010/11/exacerbacion-cutanea-dedermatomiositis.html

Considerando su fuerte asociación con patologías tumorales, se ha recomendado que los pacientes que la presenten sean investigados exhaustivamente en busca de tumores durante los próximos tres a cinco años después de su diagnóstico (36). Los tumores más frecuentes son el adenocarcinoma colorrectal (5\%) y el de pulmón (15\%) (14). En Japón, el cáncer gástrico se encuentra hasta en el $25 \%$ de los pacientes (14). Otras neoplasias asociadas son los tumores de páncreas (37), de mama, de ovario, de nasofaringe, el linfoma no hodgkiniano $(15,38,39)$ y, muy rara vez, de esófago (solo dos casos) (40, 41). Los factores predictivos de neoplasias malignas son los siguientes: edad mayor de 50 años, género masculino, úlceras, necrosis cutáneas, disfagia, aumento de la velocidad de sedimentación glomerular (VSG) o de la proteína C reactiva (PCR) (14), anticuerpos anti-155/140 (42) y elevación de la creatinfosfoquinasa sérica, (14) la cual tiene la mayor especificidad (17).

Como usualmente los autoanticuerpos característicos contra Jo-1, Mi-2 o SRP $(14,39)$ están presentes en la DMM que no cursa con neoplasias malignas, su ausencia predice una malignidad oculta (15).

\section{Eritema gyratum repens}

Es una alteración que consiste en franjas eritematosas con bordes descamativos, serpiginosas, pruriginosas y simétricas que forman anillos concéntricos $(13,25)$ con un patrón de olas o ciprés (17) (Figura 9). Es de rápido crecimiento $(-1 \mathrm{~cm}$ al día), y el diagnóstico se realiza cuando las lesiones se asocian con eosinofilia (17). En el $80 \%$ de los pacientes, hay tumores malignos, por lo cual es de gran importancia, en todos los casos, investigar una neoplasia; las más frecuentes son las de pulmón (32\%), seguidas por el cáncer de esófago $(8 \%)$ y de mama $(6 \%)$. También se ha observado en casos de cáncer de colon, estómago, recto y páncreas. En el $80 \%$ de los pacientes, esta lesión se encuentra 4 a 9 meses antes del diagnóstico del tumor $(13,25)$.

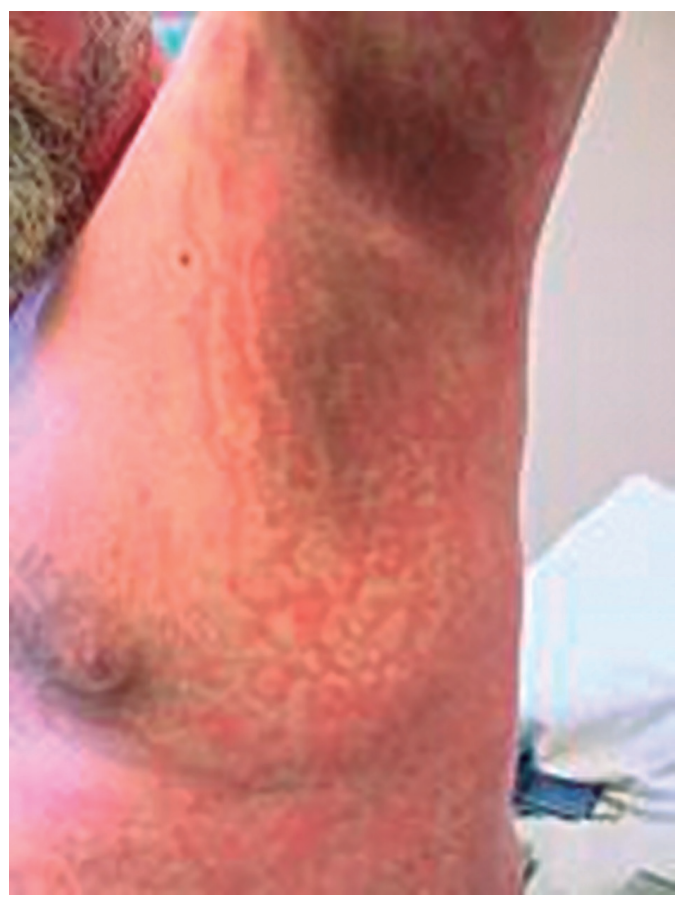

Figura 9. Eritema gyratum repens. Tomado de: https://www. onlinedermclinic.com/archive/erythema-gyratum-repens 


\section{Vasculitis leucocitoclástica cutánea}

Es la vasculitis que más se ha asociado con neoplasias (1) y que se genera por infiltración de los pequeños vasos sanguíneos, por acumulación de complejos inmunes contra el tumor o de reacción cruzada $(1,3)$. También se la conoce como "vasculitis alérgica". Clínicamente, hay púpura palpable o pápulas de color vino rojo, que evolucionan a color violáceo y dejan, finalmente, hiperpigmentación (Figura 10). Se asocian con dolor y prurito y se localizan predominantemente en miembros inferiores (1). Aunque la biopsia de piel es el estándar de oro, se debe evaluar la historia clínica y los paraclínicos (17), y solamente buscar los tumores más frecuentes según la edad del paciente (3). Los tumores malignos más frecuentes son las neoplasias hematológicas y los carcinomas de órganos urinarios, tubo gastrointestinal y pulmonar $(20 \%-26 \%)(1,3)$.

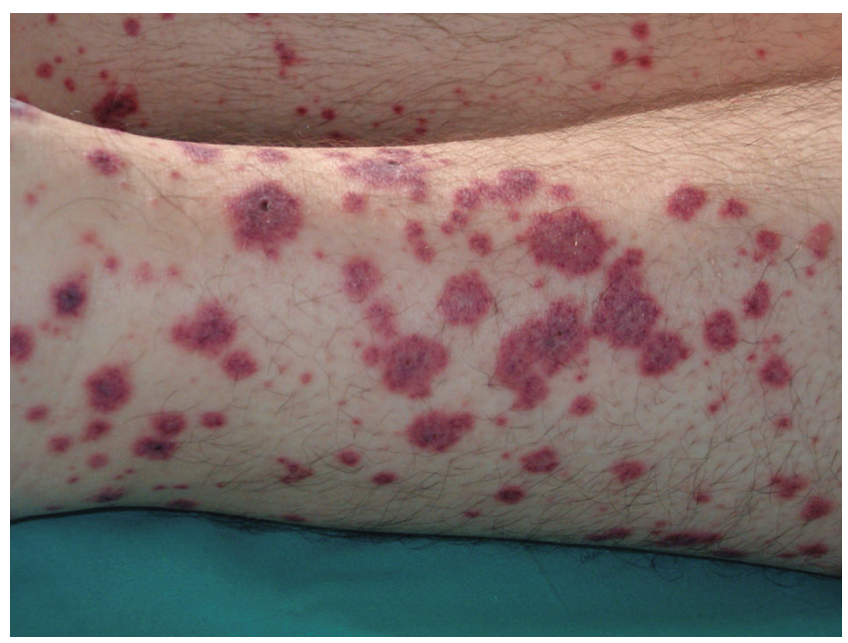

Figura 10. Vasculitis leucocitoclástica cutánea. Tomado de: http:// www.actasdermo.org/es/alertas-cutaneas-malignidades-sistemicasparte/articulo/S000173101200186X/

\section{Síndrome de Sweet}

Es una dermatosis reactiva neutrofílica febril aguda y rara que se manifiesta con la aparición súbita de placas o nódulos dolorosos eritematosos brillantes, en ocasiones en forma de pápulas, pústulas o vesículas localizadas en el rostro, el cuello o los miembros superiores (13) (Figura 11). La forma paraneoplásica es más grave y puede afectar el tronco y los miembros inferiores (18). Se presenta con fiebre o febrícula, artralgia migratoria de grandes articulaciones, leucocitosis, neutrofilia y VSG elevada (18), que mejora con corticoides sistémicos (17). La mayoría de las causas son benignas y entre ellas se encuentran las enfermedades autoinmunitarias, las infecciones y los medicamentos (17). Sin embargo, en el 10\%-20\% de los casos, se asocia con neoplasias hematológicas, aunque también se ha encontrado en tumores de testículo, colon, recto, pulmón, ovario y próstata (18).

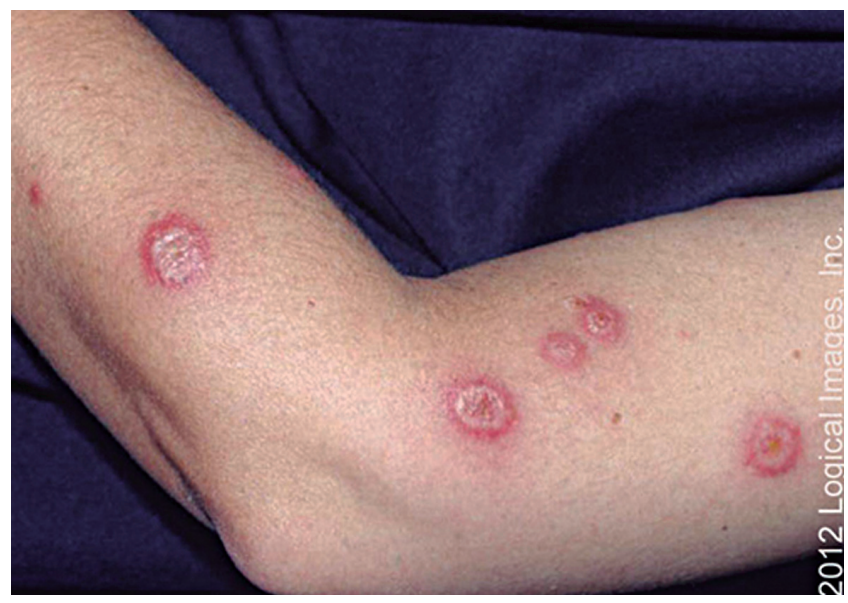

Figura 11. Síndrome de Sweet. Tomado de: http://www.elrincon delamedicinainterna.com/2013/03/dermatosis-neutrofilicas.html

\section{Pitiriasis rotunda}

Es una enfermedad rara, caracterizada por múltiples placas escamosas en el tronco, de aspecto circular, bien definidas, asintomáticas, sin cambios inflamatorios y que pueden ser hiper o hipopigmentadas (13) (Figura 12). Aparece en personas de 25 a 45 años (43) y se asocia con enfermedades crónicas como malnutrición; infecciones, como tuberculosis; y neoplasias, que incluyen carcinoma hepatocelular, gástrico, de esófago, de próstata, leucemia linfocítica crónica y mieloma múltiple (13).

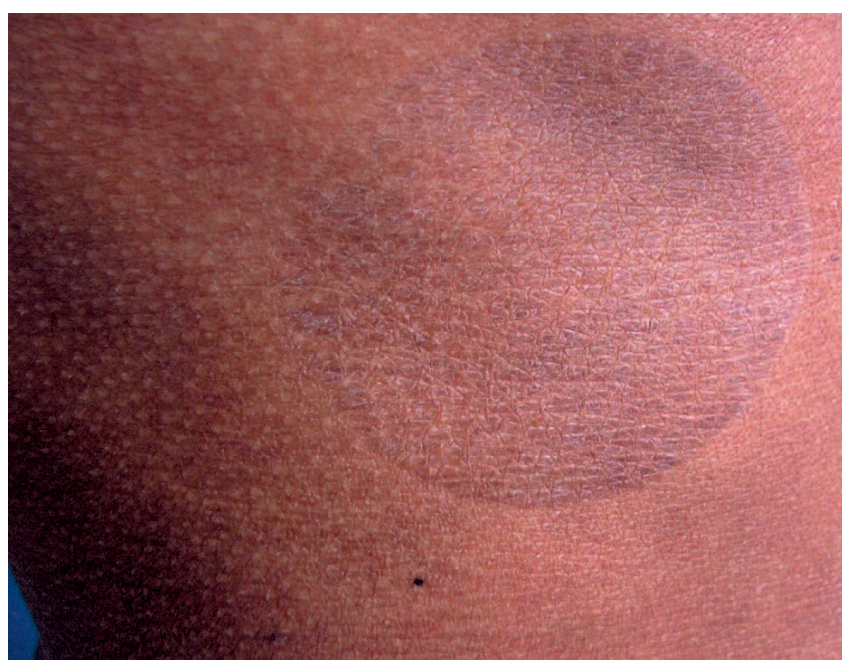

Figura 12. Pitiriasis rotunda. Tomado de: http://www.scielo.br/pdf/ abd/v82n3/v82n03a12.pdf 


\section{Eritrodermia}

Es una erupción cutánea eritematosa que afecta más del $70 \%$ de la superficie corporal (17), con alteración del flujo sanguíneo, alteraciones hemodinámicas y pérdida de proteínas y otros componentes (17). Esta dermatosis reactiva es causada por afecciones previas de la piel, medicamentos, idiopatías y neoplasias (17). Las neoplasias asociadas son leucemia, linfoma y tumores gastrointestinales, como cáncer colorrectal, gástrico, esofágico y de vesícula biliar (3). Un caso típico de eritrodermia se muestra en la Figura 13.

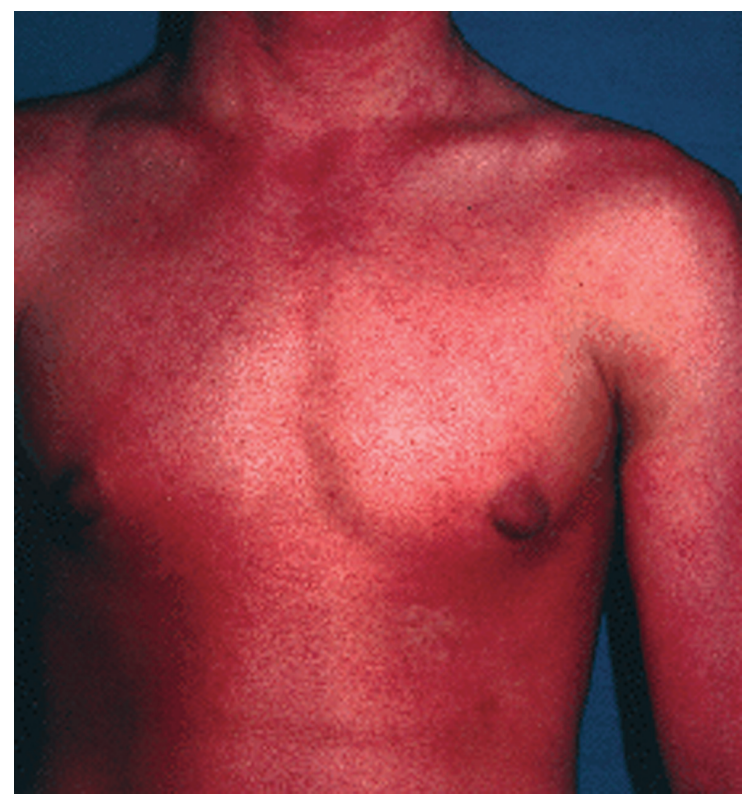

Figura 13. Eritrodermia. Tomado de: http://www.actasdermo. org/es/eritroqueratodermia-simetrica-progresiva-generalizada/ articulo/13014775/

\section{SÍNDROMES PARANEOPLÁSICOS HEMATOLÓGICOS}

Las complicaciones trombóticas y hemorrágicas constituyen la segunda causa de mortalidad en los pacientes con cáncer (44). El cáncer produce un estado de hipercoagulabilidad (45), por lo que las personas que lo padecen tienen el doble de riesgo de presentar tromboembolismo venoso (TEV) durante su vida, en comparación con las personas sin neoplasias malignas (46). La patogénesis involucra la producción por parte del tumor de sustancias procoagulantes, tales como el factor procoagulante del cáncer y las citoquinas proinflamatorias $(45,46)$. Los tumores más frecuentemente asociados son el carcinoma mucinoso del páncreas, así como también tumores pulmonares (45) y gastrointestinales, como el gástrico (45).

El $92 \%$ de los pacientes con cáncer gástrico presentan alteraciones hemostáticas en los análisis de laboratorio y, de estos, el 26,8\% tienen manifestaciones clínicas de dichas alternaciones (44), especialmente en estadios avanzados y metastásicos (45). Sin embargo, hay una gran controversia respecto de si se debe buscar un tumor oculto en pacientes con un evento trombotico sin ningún factor de riesgo asociado, ya que, entre el $2,2 \%$ y el $12 \%$ de los pacientes son diagnosticados con un tumor oculto en los 2 años siguientes a un episodio de TEV (47).

Los tres diagnósticos más comunes de cáncer después de un TEV idiopático son cáncer de pulmón, hepático y colorrectal (18,3\%, 12,3\% y 10,9\%, respectivamente) (46). En un estudio publicado hace más de 10 años, se encontró TEV en el $15 \%$ de los pacientes con cáncer y, entre ellos, la distribución de los tipos de cáncer fue la siguiente: páncreas $28 \%$, pulmón $27 \%$, gástrico $13 \%$ y de colon $3 \%$ (45).

En la actualidad, no se recomienda realizar una investigación exhaustiva de las alteraciones de la coagulación (47), aunque, al respecto, no hay estudios de rentabilidad (48). La sensibilidad en los primeros 2 años de la evaluación de rutina es del 89\% (IC del 95\%: 67\% a 99\%) (47), con una prevalencia de cero en personas menores de 40 años (45). Sin embargo, estos pacientes tienen peor pronóstico, y alrededor del $44 \%$ tiene metástasis $(47,48)$. Los pacientes con TEV que más se benefician de la búsqueda del tumor son los que no tienen otros factores de riesgo de trombosis (47, 48), los mayores de 40 años (45), con larga esperanza de vida $y$ en los que el TEV sea recurrente, o bien que tengan TVP bilateral (47). Los exámenes más rentables son la TAC abdominopélvica y la mamografía, aunque, en el estudio SOMIT, la diferencia no fue estadísticamente significativa (49).

\section{Signo de Trousseau o tromboflebitis migratoria}

Es una alteración rara, que se presenta como trombosis venosa superficial migratoria, que afecta el tórax y los miembros superiores (45). Es una señal de advertencia de enfermedad maligna avanzada, en particular de los tumores pancreáticos y pulmonares (50). Se han reportado pocos casos de cáncer gástrico, de colon (50) y de recto (51).

\section{Eosinofilia paraneoplásica}

Esta alteración, en general, es asintomática (2,3). Las neoplasias más comúnmente asociadas son los linfomas y las leucemias, pero también puede verse en tumores de pulmón, gastrointestinales y ginecológicos (3).

Adicionalmente, en el cáncer colorrectal y de estómago, se han descrito otras alteraciones, como anemia hemolítica (52). En el carcinoma escamocelular de esófago, puede aparecer un inhibidor adquirido del factor $\mathrm{V}$ de la coagulación (53), y esta alteración puede ser asintomática o causar hemorragias potencialmente mortales (53), y se sospecha 
cuando existe un aumento excesivo de los tiempos de coagulación que no mejora al administrar plasma (53). En otros cánceres gastrointestinales, se ha encontrado leucocitosis $(54,55)$, aunque se discute si realmente puede representar un síndrome paraneoplásico.

\section{SÍNDROMES PARANEOPLÁSICOS RENALES}

Se ha descrito que el síndrome nefrótico se puede encontrar en el 11\%-22\% de los pacientes con cáncer $(5,56)$. Los más frecuentes son el cáncer gástrico - en el $25 \%$ de los casos-, el pulmonar - en el 15\% de los casos-y el linfoma - en el 10\% de los casos- (56). Entre todos los pacientes con cáncer, el $50 \%$ de los casos de síndrome nefrótico paraneoplásico se asocian con cáncer pulmonar y gastroinestinal $(57,58)$. La principal lesión renal subyacente es la glomerulonefritis membranosa $(57,58)$. La resección quirúrgica del tumor mejora en hasta el $78 \%$ de los pacientes, por lo que está indicada incluso si la condición del paciente es mala (56).

Otra patología de importancia es la nefropatía membranosa, la cual representa del 6\%-22\% de los casos de compromiso renal, y los tumores más frecuentemente asociados son los gastrointestinales, junto con los carcinomas de pulmón y el cáncer de próstata (5). La comprobación de su origen paraneoplásico exige los siguientes tres criterios: mejoría con la resección, recaída con la recurrencia y un vínculo fisiopatológico (5). Existen características que hacen que una neoplasia oculta sea más probable, como la ausencia de anticuerpos anti-PLA2R1, el predominio de depósitos de IgG1/IgG2 o la presencia de más de 8 células inflamatorias por glomérulo (5). Cuando hay proteinuria, el tumor es de mal pronóstico (59). Otras nefropatías descritas son la nefropatía por inmunoglobulina A en el adenocarcinoma gástrico y de esófago (60). En ese tumor, también se ha encontrado glomerulonefritis membranoproliferativa y, además, la de rápida progresión (61). En el cáncer de colon, se ha documentado la enfermedad con cambios mínimos (61).

\section{SÍNDROMES PARANEOPLÁSICOS ENDOCRINOS}

Son los síndromes paraneoplásicos más comunes (13), aunque son poco frecuentes en la mayoría de tumores gastrointestinales. Las entidades más frecuentes son las siguientes:

\section{Síndrome de secreción inadecuada de hormona antidiurética (SIADH)}

Se presenta como síndrome paraneoplásico entre el $1 \%$ y el $2 \%$ de los pacientes con cáncer. Las células malignas secretan hormona antidiurética (ADH) (3). Se caracteriza por hipo- natremia (sodio plasmático menor de $135 \mathrm{mEq} / \mathrm{L}$, osmolaridad sérica $<275 \mathrm{mmol} / \mathrm{L})$ y volemia normal $(3,62)$. Generalmente, es asintomático o se presenta con síntomas leves, como náuseas, debilidad y cefalea, pero, en algunos casos, puede causar deterioro grave del estado de conciencia y convulsiones $(3,63)$. Las características que sugieren el diagnóstico de SIADH son las siguientes: sodio urinario superior a $40 \mathrm{mmol} / \mathrm{L}$ o una osmolalidad urinaria superior a $100 \mathrm{mOsm} / \mathrm{kg}$ de agua, con función tiroidea normal y cortisol sérico normal $(3,62)$. Este síndrome se ha vinculado más frecuentemente con cáncer de pulmón de células pequeñas, pero también se ha encontrado en tumores del tubo digestivo - los más frecuentes son los de esófago, estómago, páncreas, duodeno, colon y recto- $-(62,64-66)$.

\section{Hipercalcemia tumoral maligna}

Es uno de los síndromes paraneoplásicos más frecuentes. Se encuentra en el 20\%-30\% de los pacientes con cáncer (67). Es una alteración ominosa, ya que el $50 \%$ de los pacientes que la presentan mueren en los siguientes 30 días (67). El 80\% de los casos se deben a secreción tumoral del péptido relacionado con la paratohormona $(\mathrm{PTH})(3,67)$. El diagnóstico se debe sospechar en pacientes con un nivel de calcio sérico superior a los $10,5 \mathrm{mg} / \mathrm{dL}$ - el cual se debe corregir con la albúmina (62) -, en ausencia de calcio ionizado y acompañado de niveles reducidos de paratohormona sérica (menores de $20 \mathrm{pg} / \mathrm{mL}$ ) (67). Los síntomas de este síndrome son fatiga, náuseas, vómitos, alteración mental, insuficiencia renal, hipertensión o bradicardia (3). El síndrome es raro en tumores gastrointestinales, aunque se ha encontrado en el 1,3\% de los tumores de esófago, especialmente el carcinoma escamocelular (68).

\section{Síndrome de Cushing}

Es de origen paraneoplásico en el 5\% al 10\%, y el resto es de origen no paraneoplásico (3). Cuando es de origen paraneoplásico, la sobreproducción de la hormona corticotropa (ACTH) o de la hormona liberadora de corticotropina (CRF) proviene de las células tumorales (3). Las principales manifestaciones son hipertensión arterial, hipopotasemia, hiperglucemia, atrofia muscular proximal, atrofia cutánea generalizada, estrías violáceas y reducción de la densidad mineral ósea (3). Estos pacientes suelen ser delgados, a diferencia de los afectados por el síndrome de Cushing no paraneoplásico, los cuales presentan obesidad hasta en el $90 \%$ de los casos (3). Se debe sospechar una neoplasia extrahipofisiaria cuando hay hipercortisolismo dependiente de la ACTH que no se suprime con dexametasona y cuando en los exámenes por imágenes no se identifican lesiones hipofisiarias $(3,69)$. El tumor más frecuen- 
temente asociado es el de páncreas, el cáncer de pulmón de células pequeñas, el tumor bronquial y los tumores neuroendocrinos gastrointestinales (70). Otros casos esporádicos se asociaron con metástasis de estómago, carcinoma de células escamosas y adenocarcinoma esofágico (69).

\section{Síndrome carcinoide}

El cuadro clínico de esta alteración se caracteriza por episodios de enrojecimiento del rostro (flushing), el cuello y la parte superior del tronco, con una duración de 1 a 2 minutos; (15) diarrea, que se presenta en el $85 \%$ de los pacientes con enrojecimiento del rostro (71); disnea; broncoespasmo (15) y enfermedad valvular cardíaca (70). Este síndrome se presenta en el $8 \%$ al $10 \%$ de los pacientes con tumores neuroendocrinos del intestino medio derivados de células enterocromafines (15). Si bien los tumores son más frecuentes en el apéndice (50\%), el síndrome se encuentra principalmente en los tumores del yeyuno y del íleon y, cuando está presente, generalmente hay enfermedad metastásica, especialmente en el hígado (31). La sustancia responsable del cuadro clínico es fundamentalmente la serotonina $(15,71)$. El diagnóstico se basa en la detección de ácido 5-hidroxiindolacético en orina de 24 horas, cuya sensibilidad y especificidad son del 80\% (71). También es útil la cromogranina sérica, pero no es especi-

Tabla 1. Síndromes paraneoplásicos reumatológicos.

\begin{tabular}{|c|c|}
\hline Entidades & Tumores asociados \\
\hline Poliartritis carcinomatosa & $\begin{array}{l}\text { Neoplasias de colon (73), estómago, } \\
\text { esófago y páncreas ( } 37) \text {. }\end{array}$ \\
\hline Fascitis palmar y artritis & $\begin{array}{l}\text { Cáncer de ovario, cáncer gástrico (37), } \\
\text { de páncreas, pulmón y colon (73). }\end{array}$ \\
\hline $\begin{array}{l}\text { Reticulohistiocitosis } \\
\text { multicéntrica }^{1}\end{array}$ & $\begin{array}{l}\text { Carcinoma de pulmón, gástrico, de } \\
\text { mama, cérvix, colon y ovario (73). }\end{array}$ \\
\hline $\begin{array}{l}\text { Sinovitis simétrica } \\
\text { seronegativa remitente con } \\
\text { edema con fóvea o RS3PE }\end{array}$ & $\begin{array}{l}\text { Adenocarcinoma de estómago, } \\
\text { próstata, páncreas, endometrio (74), } \\
\text { cáncer de recto (37). }\end{array}$ \\
\hline $\begin{array}{l}\text { Osteoartropatía hipertrófica } \\
(\mathrm{OAH}) \text { o síndrome de Marie- }^{2} \\
\text { Bamberger }^{2}\end{array}$ & $\begin{array}{l}\text { Tumores intratorácicos: bronquial, } \\
\text { pleural y esofágico (77). }\end{array}$ \\
\hline Polimialgia reumática ${ }^{3}$ & Neoplasias de colon (3). \\
\hline $\begin{array}{l}\text { Fenómeno de Raynaud }{ }^{4} \\
\text { (Figura 14) }\end{array}$ & $\begin{array}{l}\text { Neoplasias de estómago, pulmón, ovario } \\
\text { y trastornos linfoproliferativos (73). }\end{array}$ \\
\hline
\end{tabular}

${ }^{1}$ Paraneoplásica en el $25 \%$ al $31 \%$ de los casos (73).

${ }^{2}$ Es una afección caracterizada por hipocratismo digital (Figura 15) o acropaquia, poliartralgias y proliferación perióstica $(75,76)$.

${ }^{3}$ Generalmente, con manifestaciones atípicas $(37,73)$.

${ }^{4}$ En pacientes mayores de 50 años. Clínicamente, es asimétrico y con necrosis digital, de 7 a 9 meses previos al diagnóstico del tumor (73). fica de este síndrome y tiene una gran cantidad de falsos positivos que reducen su utilidad diagnóstica (71).

Otros síndromes endocrinos asociados con tumores gastrointestinales son la acromegalia por elevación de la hormona de crecimiento y del factor insulínico de crecimiento tipo (IGF-1) (72). Los tumores más frecuentemente asociados son los gástricos y los pulmonares (63). En mujeres con cáncer de colon, se ha encontrado producción ectópica de prolactina, que ocasiona galactorrea y amenorrea y, cuando se presenta en los hombres, produce ginecomastia e hipogonadismo (63). En tumores gástricos y estromales gastrointestinales (GIST), se ha encontrado hipoglucemia (72).

\section{SÍNDROMES PARANEOPLÁSICOS REUMATOLÓGICOS}

Son síndromes infrecuentes. Los mejor documentados se muestran en la Tabla 1.

\section{SÍNDROMES PARANEOPLÁSICOS NEUROLÓGICOS}

Son muy raros y afectan del $0,01 \%$ al $1 \%$ de los pacientes con cáncer (35). Su patogénesis está relacionada con la presencia de antígenos onconeurales, presentes en el sistema nervioso y en el tumor $(4,35)$. En el $60 \%-70 \%$ de los casos, las alteraciones neurológicas se identifican antes que el tumor $(4,78)$. Pueden clasificarse como síndromes clásicos y no

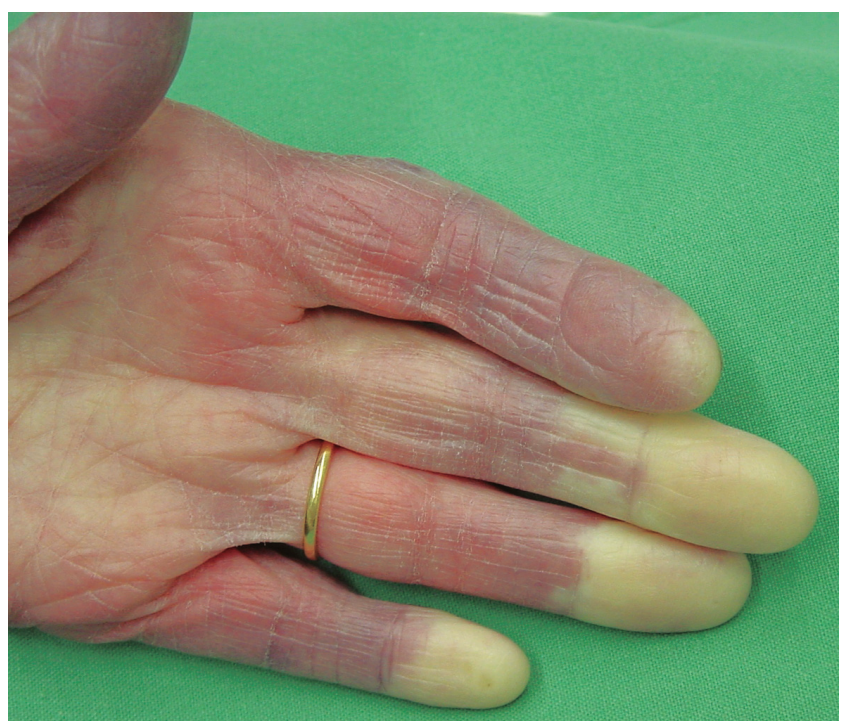

Figura 14. El fenómeno de Raynaud consiste en la decoloración transitoria de los dedos de las manos y los pies secundaria a trastornos vasomotores. Clásicamente, tiene tres fases. Se inicia con vasoconstricción, que provoca palidez, seguida de cianosis secundaria a hipoxia del área comprometida y, luego, enrojecimiento cuando cesa la vasoconstricción y la sangre vuelve a fluir. Tomado de: http://angiogrup. es/patologias/arterioaptias/sindrome-de-raynaoud/ 


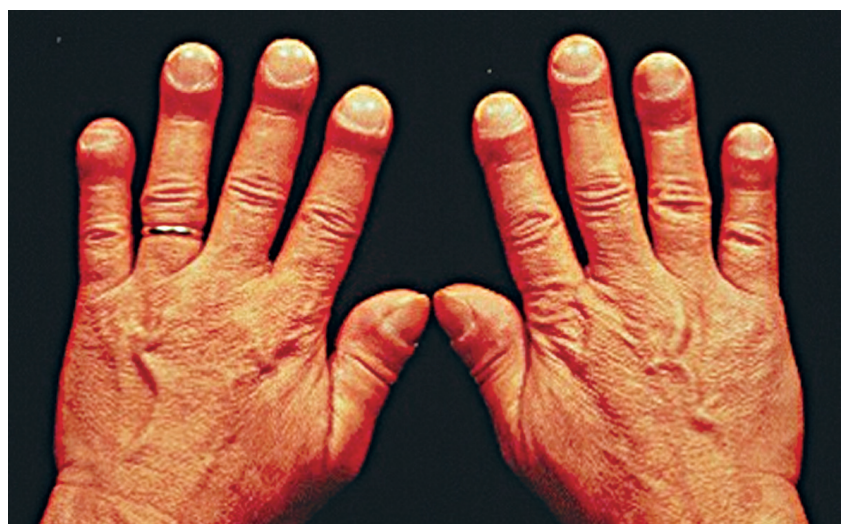

Figura 15. Hipocratismo digital. Tomado de: http://www.oncoprof. net/Generale2000/g04_Diagnostic/Symptomes/Index/gb04-sympix-01.html

clásicos (78). Los clásicos son: encefalomielitis, encefalitis límbica, degeneración cerebelosa subaguda, síndrome de opsoclono-mioclono, neuropatía sensitiva subaguda, pseudoobstrucción intestinal crónica, síndrome miasténico de Lambert-Eaton y dermatomiositis (35). Las neoplasias asociadas incluyen cáncer de pulmón de células pequeñas, timoma, tumores de mama y ginecológicos, linfoma hodgkiniano, mieloma múltiple y cáncer de colon (79).

Aunque no son frecuentes en tumores GI, se han reportado múltiples casos en tumores neuroendocrinos del tubo gastrointestinal, como neuromielitis óptica (intestino delgado) (80), tumores gástricos (81); retinopatía asociada con cáncer (CAR) (intestino delgado) (82) y encefalitis del tronco encefálico (recto) (83).

Sin embargo, existen numerosos reportes de caso en los que se han relacionado con tumores gastrointestinales, los cuales se dividen según el nivel que afecten, como el sistema nervioso central (Tabla 2) o el sistema nervioso periférico (Tabla 3).

\section{SÍNDROMES PARANEOPLÁSICOS GASTROINTESTINALES}

Son una extensión del síndrome paraneoplásico neurológico producto de la neuropatía visceral por daño de las neuronas del plexo mientérico (35). Esta se manifiesta como pseudoacalasia (102), gastroparesia y pseudoobstrucción intestinal $(38,103,104)$. La gastroparesia es la más común (105), a diferencia de la pseudoacalasia paraneoplásica, que es muy rara ( 1 persona en cada 750000$)$ (106). Alrededor del $30 \%$ de los pacientes tienen alteración de la motilidad (107) y manifiestan estreñimiento grave, distensión abdominal, disfagia, náuseas, vómitos (35) y dolor abdominal (78). Si
Tabla 2. Síndromes paraneoplásicos del sistema nervioso central.

\begin{tabular}{ll}
\hline \multicolumn{1}{c}{ Entidades } & \multicolumn{1}{c}{ Tumores asociados } \\
\hline $\begin{array}{l}\text { Síndrome de degeneración } \\
\text { cerebelosa paraneoplásica }\end{array}$ & $\begin{array}{l}\text { Adenocarcinoma esofágico }(84,85), \\
\text { gástrico, de colon }(35) \text { y linfoma gástrico } \\
\text { difuso de linfocitos B grandes }(86,87) . \\
\text { Carcinoma esofágico }(68,88) .\end{array}$ \\
Encefalits & $\begin{array}{l}\text { Carcinoma de células pequeñas y, } \\
\text { adenocarcinoma de esófago }(89,90,91) \\
\text { y adenocarcinoma colorrectal }(92,93) .\end{array}$ \\
$\begin{array}{l}\text { Síndrome de opsoclono- } \\
\text { mioclono }\end{array}$ & $\begin{array}{l}\text { Carcinoma escamocelular de esófago } \\
\text { (94) y adenocarcinoma gástrico }(95) .\end{array}$ \\
$\begin{array}{l}\text { Neuropatía óptica y } \\
\text { retinopatía } \\
\text { Mielopatía necrosante }\end{array}$ & Adenocarcinoma de colon $(96,97)$. \\
\hline
\end{tabular}

Tabla 3. Síndromes neurológicos paraneoplásicos del sistema nervioso periférico.

\begin{tabular}{ll}
\hline \multicolumn{1}{c}{ Entidades } & \multicolumn{1}{c}{ Tumores asociados } \\
\hline $\begin{array}{l}\text { Polineuropatía sensitivo- } \\
\text { motora }\end{array}$ & Cáncer de estómago y esófago (99). \\
$\begin{array}{l}\text { Síndrome miasténico de } \\
\text { Lambert-Eaton }\end{array}$ & Cáncer de recto (100). \\
$\begin{array}{l}\text { Síndrome de la persona } \\
\text { rígida }\end{array}$ & Cáncer de colon (35). \\
$\begin{array}{l}\text { Polimiositis }{ }^{1} \\
\end{array}$ & $\begin{array}{l}\text { Linfoma no hodgkiniano, cáncer de pulmón, } \\
\text { de vejiga (38), y, con menor frecuencia, } \\
\text { tumores gastrointestinales (101). }\end{array}$ \\
\hline
\end{tabular}

${ }^{1}$ Es uno de los síndromes paraneoplásicos neurológicos más frecuentes. Del $15 \%$ al 20\% de los casos son paraneoplásicos, con predominio en los mayores de 50 años (38).

se detectan anticuerpos anti-HuD o anti-CV2, se debe iniciar la búsqueda de una malignidad (35). Los tumores más frecuentes son cáncer de pulmón de células pequeñas (78) timoma y cáncer de mama (35), pero también se ha relacionado con cáncer gástrico, pancreático, de vesícula biliar, esofágico (108) y tumores carcinoides (103).

\section{CONCLUSIONES}

Los tumores del tubo gastrointestinal pueden producir casi cualquier síndrome paraneoplásico, resumidos en la Tabla 4, pero en diferente magnitud, la cual se ha mencionado en detalle en este trabajo. Teniendo en cuenta lo anterior, se debe realizar una búsqueda básica, se deben detectar los signos de alarma y el riesgo de malignidad, y, luego, se debe realizar una búsqueda más específica con los síndromes paraneoplásicos más frecuentes, como la CAC o la AN maligna. 
Tabla 4. Síndromes paraneoplásicos asociados con tumores gastrointestinales.

\begin{tabular}{|c|c|}
\hline Síndromes paraneoplásicos & Tumores que los producen \\
\hline Caquexia & Adenocarcinoma gastrointestinal o pancreático. \\
\hline Acantosis nigricans & Adenocarcinoma gástrico, de esófago, páncreas, hígado y vía biliar. \\
\hline Palmas de intestino & Adenocarcinoma gástrico. \\
\hline Síndrome de Leser-Trélat & Adenocarcinoma gástrico, de colon, recto, esófago, duodeno, páncreas y vesícula e hígado. \\
\hline Síndrome de Bazex & De esófago y colon, gástrico y hepatobiliar. \\
\hline Hipertricosis lanuginosa paraneoplásica & Colon, recto, páncreas y vesícula biliar. \\
\hline Pénfigo paraneoplásico & Adenocarcinoma de colon y páncreas. \\
\hline Dermatomiositis paraneoplásica & Colorrectal, gástrico, de páncreas y esófago. \\
\hline Eritema gyratum repens & Gástrico, de esófago, colon, recto y páncreas. \\
\hline Vasculitis leucocitoclástica cutánea & Tubo gastrointestinal. \\
\hline Síndrome de Sweet & Colon y recto. \\
\hline Pitiriasis rotunda & Carcinoma hepatocelular, gástrico y de esófago. \\
\hline Eritrodermia & Colorrectal, gástrico, esofágico y de vesícula biliar. \\
\hline TEV & Gástrico, hepático, colorrectal y de páncreas. \\
\hline Signo de Trousseau & Gástrico, de páncreas, colon y recto. \\
\hline Eosinofilia paraneoplásica & Tumores gastrointestinales. \\
\hline Anemia hemolítica & Cáncer colorrectal y de estómago. \\
\hline Inhibidor adquirido del factor $V$ de la coagulación & Carcinoma escamocelular de esófago. \\
\hline Glomerulonefritis membranosa & Cáncer gástrico. \\
\hline Nefropatía por inmunoglobulina $\mathrm{A}$ & Adenocarcinoma gástrico y de esófago. \\
\hline $\begin{array}{l}\text { Síndrome de secreción inadecuada de hormona } \\
\text { antidiurética }\end{array}$ & Gástrico, de esófago, páncreas, duodeno, colon y recto. \\
\hline Hipercalcemia tumoral maligna & Carcinoma escamocelular de esófago. \\
\hline Síndrome de Cushing & Tumores neuroendocrinos, de estómago y esófago. \\
\hline Síndrome carcinoide & Tumores neuroendocrinos. \\
\hline Poliartritis carcinomatosa & Colon, estómago, esófago y páncreas. \\
\hline Fascitis palmar y artritis & Cáncer gástrico, de páncreas y colon. \\
\hline Reticulohistiocitosis multicéntrica & Gástrico y de colon. \\
\hline Sinovitis simétrica seronegativa (RS3PE) & Estómago, páncreas y recto. \\
\hline Osteoartropatía hipertrófica $(\mathrm{OAH})$ & Esofágico. \\
\hline Polimialgia reumática & Neoplasias de colon. \\
\hline Síndrome de Raynaud & Cáncer gástrico. \\
\hline Sindromes paraneoplásicos neurológicos & Cáncer gástrico, de esófago y colon, y tumores neuroendocrinos. \\
\hline Síndromes paraneoplásicos gastrointestinales & Gástrico, pancreático, de vesícula biliar, esofágico y tumor carcinoide. \\
\hline
\end{tabular}

\section{REFERENCIAS}

1. Kanaji N, Watanabe N, Kita N, et al. Paraneoplastic syndromes associated with lung cancer. World J Clin Oncol. 2014;5(3):197-223. https://doi.org/10.5306/wjco.v5.i3.197

2. Jameson JL, Longo DL. Paraneoplastic syndromes: endocrinologic/hematologic. En: Kasper D, Fauci A, Hauser S, et al. (editores). Harrison's principles of internal medicine (19. ${ }^{a}$ edición). Nueva York: McGraw-Hill Education; 2015.
3. PelosofLC, Gerber DE. Paraneoplastic syndromes: an approach to diagnosis and treatment. Mayo Clin Proc. 2010;85(9):83854. https://doi.org/10.4065/mcp.2010.0099

4. Darnell RB, Posner JB. Paraneoplastic syndromes involving the nervous system. The New England Journal of Medicine. 2003;349(16):1543-54. https://doi.org/10.1056/ NEJMra023009

5. Cambier JF, Ronco P. Onco-nephrology: glomerular diseases with cancer. Clin J Am Soc Nephrol. 2012;7(10):170112. https://doi.org/10.2215/CJN.03770412 
6. Aoyagi T, Terracina KP, Raza A, et al. Cancer cachexia, mechanism and treatment. World J Gastrointest Oncol. 2015;7(4):17-29.

7. Tsoli M, Robertson G. Cancer cachexia: malignant inflammation, tumorkines, and metabolic mayhem. Tren Endocr Met. 2013;24(4):174-83. https://doi.org/10.1016/j. tem.2012.10.006

8. Nicolini A, Ferrari P, Masoni MC, et al. Malnutrition, anorexia and cachexia in cancer patients: a mini-review on pathogenesis and treatment. Biomed Pharmac. 2013;67(8):80717. https://doi.org/10.1016/j.biopha.2013.08.005

9. Petruzzelli M, Schweiger M, Schreiber R, et al. A switch from white to brown fat increases energy expenditure in cancer-associated cachexia. Cell Metab. 2014;20(3):43347. https://doi.org/10.1016/j.cmet.2014.06.011

10. Al-ZoughbiW, HuangJ, Paramasivan GS, et al. Tumor macroenvironment and metabolism. Sem Oncol. 2014;41(2):281-95. https://doi.org/10.1053/j.seminoncol.2014.02.005

11. Morley JE, Farr SA. Cachexia and neuropeptide Y. Nutrition. 2008;24(9):815-9. https://doi.org/10.1016/j. nut.2008.06.020

12. Richards $\mathrm{CH}$, Roxburgh CSD, MacMillan MT, et al. The relationships between body composition and the systemic inflammatory response in patients with primary operable colorectal cancer. PLoS ONE. 2012;7(8):e41883. https:// doi.org/10.1371/journal.pone.0041883

13. Silva JA, Mesquita K de C, Igreja AC, et al. Paraneoplastic cutaneous manifestations: concepts and updates. Anais Brasileiros de Dermatologia. 2013;88(1):9-22. https://doi. org/10.1590/S0365-05962013000100001

14. Dourmishev LA, Draganov PV. Paraneoplastic dermatological manifestation of gastrointestinal malignancies. World J Gastroenterol. 2009;15(35):4372-9. https://doi. org/10.3748/wjg.15.4372

15. Shah KR, Boland CR, Patel M, et al. Cutaneous manifestations of gastrointestinal disease: part I. J Am Acad Dermatol. 2013;68(2):189.e1-21. https://doi.org/10.1016/j. jaad.2012.10.037

16. Phiske MM. An approach to acanthosis nigricans. Indian Dermatology Online Journal. 2014;5(3):239-49. https:// doi.org/10.4103/2229-5178.137765

17. Faizal M. Manifestaciones cutáneas de neoplasias extracutaneas y paraneoplasias. En: Cáncer de la piel. Bogotá: Universidad Nacional de Colombia; 2014. pp. 385-546.

18. Woo VL, Abdelsayed R. Oral manifestations of internal malignancy and paraneoplastic syndromes. Dent Clin North Am. 2008;52(1):203-30. https://doi.org/10.1016/j. cden.2007.09.005

19. Yosipovitch G. Chronic pruritus: a paraneoplastic sign. Dermatol Ther. 2010;23(6):590-6. https://doi. org/10.1111/j.1529-8019.2010.01366.x

20. Yang YH, Zhang RZ, Kang DH, et al. Three paraneoplastic signs in the same patient with gastric adenocarcinoma. Dermatol Online Journal. 2013;19(7):15.

21. Stawczyk-Macieja M, Szczerkowska-Dobosz A, Nowicki R, et al. Malignant acanthosis nigricans, florid cutaneous papilloma- tosis and tripe palms syndrome associated with gastric adenocarcinoma. Postpy Dermatologii I Alergologii. 2014;31(1):568. https://doi.org/10.5114/pdia.2014.40663

22. Krawczyk M, Mykała-Cieśla J, Kołodziej-Jaskuła A. Acanthosis nigricans as a paraneoplastic syndrome. Case reports and review of literature. Polskie Archiwum Medycyny Wewnętrznej. 2009;119(3):180-3.

23. Zhang N, Qian Y, Feng AP. Acanthosis nigricans, tripe palms, and sign of Leser-Trélat in a patient with gastric adenocarcinoma: case report and literature review in China. Int J Dermatol. 2015;54(3):338-42. https://doi.org/10.1111/ijd.12034

24. Ponti G, Luppi G, Losi L, et al. Leser-Trelat syndrome in patients affected by six multiple metachronous primitive cancers. J Hematol Oncol 2010;3:2. https://doi. org/10.1186/1756-8722-3-2

25. Ramos E, Silva M, Carvalho JC, et al. Cutaneous paraneoplasia. Clin Dermatol. 2011;29(5):541-7. https://doi. org/10.1016/j.clindermatol.2010.09.022

26. Nanda A, Mamon HJ, Fuchs CS. Sign of Leser-Trelat in newly diagnosed advanced gastric adenocarcinoma. J Clin Oncol 2008;26(30):4992-3. https://doi.org/10.1200/ JCO.2008.17.9143

27. Medenica L, Gajic-Veljic M, Skiljevic D, et al. Acrokeratosis paraneoplastica Bazex syndrome associated with esophageal squamocellular carcinoma. Vojnosanitetski pregled. 2008;65(6):485-7. https://doi.org/10.2298/VSP0806485M

28. Poligone B, Christensen SR, Lazova R, et al. Bazex syndrome (acrokeratosis paraneoplastica). Lancet. 2007;369(9560):530. https://doi.org/10.1016/S0140-6736(07)60240-2

29. Rao R, Shenoi SD. Acrokeratosis paraneoplastica (Bazex syndrome): an atypical presentation. Dermatology Online Journal. 2004;10(1):21.

30. Rodrígues IA Jr., Gresta LT, Cruz RC, et al. Bazex syndrome. Anais Brasileiros de Bermatologia. 2013;88(6-1):209-11. https://doi.org/10.1590/abd1806-4841.20132488

31. Mirowski GW, Leblanc J, Mark LA. Oral disease and oralcutaneous manifestations of gastrointestinal and liver disease. En: Feldman M, Friedman LS, Brandt LJ (editores). Sleisenger and Fordtran's gastrointestinal and liver disease: pathophysiology, diagnosis, management (10. ${ }^{a}$ edición). Estados Unidos: Elsevier; 2016. pp. 377-962.

32. Saad N, Hot A, Ninet J, et al. Acquired hypertrichosis lanuginosa and gastric adenocarcinoma. Annales de Dermatologie et de Venereologie. 2007;134(1):55-8. https://doi.org/10.1016/S0151-9638(07)88991-5

33. Lee SE, Kim S-C. Paraneoplastic pemphigus. Dermatologica Sinica. 2010;28(1):1-14. https://doi.org/10.1016/S10278117(10)60001-8

34. Espinoza-Cobos JC, Pérez-Figueroa J, Zuniga-Ahuet G, et al. Oropharyngeal dysphagia as a first manifestation of dermatomyositis associated with colon cancer. Rev Gastroenterol Mex. 2010;75(4):522-7.

35. Martel S, De Angelis F, Lapointe E, et al. Paraneoplastic neurologic syndromes: clinical presentation and management. Curr Prob Cancer. 2014;38(4):115-34. https://doi. org/10.1016/j.currproblcancer.2014.08.002 
36. Femia AN, Vleugels RA, Callen JP. Cutaneous dermatomyositis: an updated review of treatment options and internal associations. Am J Clin Dermatol. 2013;14(4):291-313. https://doi.org/10.1007/s40257-013-0028-6

37. Mayet WJ. Gastrointestinal tumors. Clinical manifestations of paraneoplastic rheumatic symptoms. Zeitschrift für Rheumatologie. 2011;70(7):567-72. https://doi.org/10.1007/s00393-011-0812-8

38. Voltz R. Paraneoplastic neurological syndromes: an update on diagnosis, pathogenesis, and therapy. Lancet Neurol. 2002;1(5):294-305. https://doi.org/10.1016/S14744422(02)00135-7

39. Leypoldt F, Wandinger KP. Paraneoplastic neurological syndromes. Clin Exper Immunol. 2014;175(3):336-48. https://doi.org/10.1111/cei.12185

40. Terada T. Signet-ring cell carcinoma of the esophagus in dermatomyositis: a case report with immunohistochemical study. J Gastrointest Cancer. 2013;44(4):489-90. https://doi.org/10.1007/s12029-012-9469-z / https:// doi.org/10.1007/s12029-012-9473-3

41. Harrison BA, Heck SI, Hood AF. A fatal case of dermatomyositis with underlying metastatic esophageal adenocarcinoma. Cutis. 2008;81(1):26-8.

42. Di Rollo D, Abeni D, Tracanna M, et al. Cancer risk in dermatomyositis: a systematic review of the literature. Giornale Italiano di Dermatologia e Venereologia: organo ufficiale, Società Italiana di Dermatologia e Sifilografia. 2014;149(5):525-37.

43. Lefkowitz EG, Natow AJ. Pityriasis rotunda: a case report of familial disease in an American-born black patient. Case Reports in Dermatology. 2016;8(1):71-74. https://doi. org/10.1159/000445043

44. Kovacova E, Kinova S, Duris I, et al. General changes in hemostasis in gastric cancer. Bratislavske Lekarske Listy. 2009; 110(4):215-21.

45. Caine GJ, Stonelake PS, Lip GYH, et al. The hypercoagulable state of malignancy: pathogenesis and current debate. Neoplasia. 2002;4(6):465-73. https://doi.org/10.1038/ sj.neo. 7900263

46. Chung WS, Lin CL, Hsu WH, et al. Idiopathic venous thromboembolism: a potential surrogate for occult cancer. 2014;107(7):529-36.

47. Monreal M, Trujillo-Santos J. Screening for occult cancer in patients with acute venous thromboembolism. Curr Opin Pulmon Med. 2007;13(5):368-71. https://doi. org/10.1097/MCP.0b013e3282058b6f

48. TimpJF, Braekkan SK, Versteeg HH, et al. Epidemiology of cancer-associated venous thrombosis. Blood. 2013;122(10):171223. https://doi.org/10.1182/blood-2013-04-460121

49. Di Nisio M, Otten HM, Piccioli A, et al. Decision analysis for cancer screening in idiopathic venous thromboembolism. J Thromb Haem. 2005;3(11):2391-6. https://doi. org/10.1111/j.1538-7836.2005.01606.x

50. Thrumurthy SG, Anuruddha AH, De Zoysa MI, et al. Unexpected outcome from Trousseau syndrome. BMC Surgery. 2011;11:1. https://doi.org/10.1186/1471-2482-11-1
51. Sierra-Montenegro E, Sierra-Luzuriaga G, Calle-Loffredo D, et al. Rectal cancer and Trousseau syndrome. Case report. Cirugía y Cirujanos. 2013;81(3):242-5.

52. Puthenparambil J, Lechner K, Kornek G. Autoimmune hemolytic anemia as a paraneoplastic phenomenon in solid tumors: a critical analysis of 52 cases reported in the literature. Wiener Klinische Wochenschrift. 2010;122(7-8):22936. https://doi.org/10.1007/s00508-010-1319-z

53. Ahmadinejad M, Roushan N. Acquired factor V inhibitor developing in a patient with esophageal squamous cell carcinoma. Blood Coag Fibrin. 2013;24(1):97-9. https://doi. org/10.1097/MBC.0b013e328359bc59

54. Callacondo D, Ganoza-Salas A, Anicama-Lima W, et al. Primary squamous cell carcinoma of the stomach with paraneoplastic leukocytosis: a case report and review of literature. Hum Pathol. 2009;40(10):1494-8. https://doi. org/10.1016/j.humpath.2009.02.014

55. Chakraborty S, Keenportz B, Woodward S, et al. Paraneoplastic leukemoid reaction in solid tumors. Am J Clin Oncol. 2015;38(3):326-30. https://doi.org/10.1097/ COC.0b013e3182a530dd

56. Takane K, Midorikawa Y, Yamazaki S, et al. Gastrointestinal stromal tumor with nephrotic syndrome as a paraneoplastic syndrome: a case report. J Med Case Rep. 2014;8:108-13. https://doi.org/10.1186/1752-1947-8-108

57. Alpers CE, Cotran RS. Neoplasia and glomerular injury. Kidney Intern. 1986;30(4):465-73. https://doi. org/10.1038/ki.1986.209

58. Bacchetta J, Juillard L, Cochat P, et al. Paraneoplastic glomerular diseases and malignancies. Crit Rev Oncol/ Hematol. 2009;70(1):39-58. https://doi.org/10.1016/j. critrevonc.2008.08.003

59. Sawyer N, Wadsworth J, Wijnen M, et al. Prevalence, concentration, and prognostic importance of proteinuria in patients with malignancies. Br Med J. 1988;296(6632):1295-8. https://doi.org/10.1136/bmj.296.6632.1295

60. Kocyigit I, Dortdudak S, Eroglu E, et al. Immunoglobulin A nephropathy could be a clue for the recurrence of gastric adenocarcinoma. Nefrología: publicación oficial de la Sociedad Espanola Nefrología. 2013;33(6):853-5.

61. Lien YH, Lai LW. Pathogenesis, diagnosis and management of paraneoplastic glomerulonephritis. Nat Rev Nephrol. 2011;7(2):85-95. https://doi.org/10.1038/ nrneph.2010.171

62. Rosner MH, Dalkin AC. Electrolyte disorders associated with cancer. Adv Chr Kidney Dis. 21(1):7-17.

63. Yeung S, Gagel R. Endocrine paraneoplastic syndromes ("ectopic" hormone production). En: Kufe D, Pollock R, Weichselbaum R (editores). Holland-Frei cancer medicine (6. edición). 2003.

64. Hwang K, Jeon DH, Jang HN, et al. Inappropriate antidiuretic hormone syndrome presenting as ectopic antidiuretic hormone-secreting gastric adenocarcinoma: a case report. J Med Case Rep. 2014;8:185. https://doi.org/10.1186/17521947-8-185 
65. Ando T, Hosokawa A, Yamawaki H, et al. Esophageal smallcell carcinoma with syndrome of inappropriate secretion of antidiuretic hormone. Internal medicine (Tokyo, Japan). 2011;50(10):1099-103. https://doi.org/10.2169/internalmedicine.50.4694

66. Murakami S, Togo S, Yasuda S, et al. The syndrome of inappropriate secretion of antidiuretic hormone by rectal cancer. A case report. Jap J Surg. 1987;17(4):293-6. https://doi.org/10.1007/BF02470703

67. Stewart AF. Clinical practice. Hypercalcemia associated with cancer. The New Engl J Med. 2005;352(4):373-9. https://doi.org/10.1056/NEJMcp042806

68. Nakajima N, Ueda M, Nagayama $H$, et al. Posterior reversible encephalopathy syndrome due to hypercalcemia associated with parathyroid hormone-related peptide: a case report and review of the literature. Internal Medicine. 2013;52(21):2465-8. https://doi.org/10.2169/internalmedicine.52.0444

69. Baas JM, Kapiteijn E, Pereira AM, et al. Atypical Cushing's syndrome caused by ectopic ACTH secretion of an oesophageal adenocarcinoma. The Netherlands Journal of Medicine. 2010;68(6):265-7.

70. Witek P, Witek J, Zielinski G, et al. Ectopic Cushing's syndrome in light of modern diagnostic techniques and treatment options. Neuro Endocrinology Letters. 2015;36(3):201-8

71. Jensen RT, Norton JA, Oberg K. Neuroendocrine tumors. En: Feldman M, Friedman LS, Brandt LJ (editores). Sleisenger and fordtran's gastrointestinal and liver disease: pathophysiology, diagnosis, management (10. ${ }^{\text {a }}$ edición). Estados Unidos: Elsevier; 2016: 501-41.

72. Iglesias P, Diez JJ. Management of endocrine disease: a clinical update on tumor-induced hypoglycemia. European Journal of Endocrinology/European Federation of Endocrine Societies. 2014;170(4):R147-57.

73. Bojinca V, Janta I. Rheumatic diseases and malignancies. Maedica. 2012;7(4):364-71.

74. Nagasawa K. Rheumatic manifestations in paraneoplastic syndrome. Internal Medicine (Tokyo, Japan). 2000;39(9):685-6. https://doi.org/10.2169/internalmedicine.39.685

75. Nuno Mateo FJ, Noval Menéndez J, Campoamor Serrano MT, et al. Forty-eight year oldmale with dysphagia, general syndrome and finger clubbing. Revista Clínica Española. 2003;203(2):95-6.

76. Silva L, Andreu JL, Muñoz P, et al. Hypertrophic osteoarthropathy associated with gastrointestinal stromal tumour. Annals of the Rheumatic Diseases. 2006;65(5):681-2. https://doi.org/10.1136/ard.2005.044859

77. Manger B, Lindner A, Manger K, et al. Hypertrophic osteoarthropathy. Bamberger-Marie disease. Zeitschrift für Rheumatologie. 2011;70(7):554-60. https://doi. org/10.1007/s00393-011-0813-7

78. Storstein A, Vedeler CA. Paraneoplastic neurological syndromes. Tidsskrift for den Norske Laegeforening: tidsskrift for praktisk medicin, ny raekke. 2009;129(6):524-8. https://doi.org/10.4045/tidsskr.09.35653

79. Foxx-Ornestein AE. Ileus and pseudo-obstruction. En: Feldman M, Friedman LS, Brandt LJ (editores). Sleisenger and Fordtran's gastrointestinal and liver disease: pathophysiology, diagnosis, management (1. a edición). Estados Unidos: Elsevier; 2016: 2171-956.

80. Figueroa M, Guo Y, Tselis A, et al. Paraneoplastic neuromyelitis optica spectrum disorder associated with metastatic carcinoid expressing aquaporin-4. JAMA Neurology. 2014;71(4):495-8. https://doi.org/10.1001/jamaneurol.2013.6331

81. Al-Harbi T, Al-Sarawi A, Binfalah M, et al. Paraneoplastic neuromyelitis optica spectrum disorder associated with stomach carcinoid tumor. Hematology/Oncology and Stem Cell Therapy. 2014;7(3):116-9. https://doi.org/10.1016/j. hemonc.2014.06.001

82. Ogra S, Sharp D, Danesh-Meyer H. Autoimmune retinopathy associated with carcinoid tumour of the small bowel. Journal of Clinical Neuroscience: official journal of the Neurosurgical Society of Australasia. 2014;21(2):358-60. https://doi.org/10.1016/j.jocn.2013.07.002

83. Boch M, Rinke A, Rexin P, et al. Paraneoplastic brainstem encephalitis in a patient with exceptionally long course of a metastasized neuroendocrine rectum neoplasm. BMC Cancer. 2014;14:691-5. https://doi.org/10.1186/1471-2407-14-691

84. Xia K, Saltzman JR, Carr-Locke DL. Anti-Yo antibodymediated paraneoplastic cerebellar degeneration in a man with esophageal adenocarcinoma. Med Gen Med. 2003;5(3): 18 .

85. Debes JD, Lagarde SM, Hulsenboom E, et al. Anti-Yo-associated paraneoplastic cerebellar degeneration in a man with adenocarcinoma of the gastroesophageal junction. Digestive Surgery. 2007;24(5):395-7. https://doi.org/10.1159/000107782

86. Nomani AZ, Wazir M, Kashmir SB, et al. Diffuse large B-cell lymphoma of stomach presenting with paraneoplastic cerebellar degeneration syndrome. Journal of the College of Physicians and Surgeons-Pakistan. 2014;24(1):S11-3.

87. Lakshmaiah KC, Viveka BK, Anil Kumar N, et al. Gastric diffuse large $\mathrm{B}$ cell lymphoma presenting as paraneoplastic cerebellar degeneration: case report and review of literature. J Egyp Nat Cancer Inst. 2013;25(4):231-5. https://doi. org/10.1016/j.jnci.2013.07.001

88. Mundiyanapurath S, Jarius S, Probst C, et al. GABA-Breceptor antibodies in paraneoplastic brainstem encephalitis. Journal of Neuroimmunology. 2013;259(1-2):88-91. https://doi.org/10.1016/j.jneuroim.2013.04.004

89. Shirafuji T, Kanda F, Sekiguchi K, et al. Anti-Hu-associated paraneoplastic encephalomyelitis with esophageal small cell carcinoma. Internal Medicine. 2012;51(17):2423-7. https://doi.org/10.2169/internalmedicine.51.6884

90. Gultekin SH, Rosenfeld MR, Voltz R, et al. Paraneoplastic limbic encephalitis: neurological symptoms, immunological findings and tumour association in 50 patients. Brain. 2000; 123(7):148194. https://doi.org/10.1093/brain/123.7.1481 
91. Menezes RB, de Lucena AF, Maia FM, et al. Limbic encephalitis as the presenting symptom of oesophageal adenocarcinoma: another cancer to search? BMJ Case Reports 2013. https://doi.org/10.1136/bcr-2012-008201

92. Aggarwal I, Beller J, Tzimas D. A case of confusion. Gastroenterology. 2014;147(6):e5-6. https://doi. org/10.1053/j.gastro.2014.06.036

93. Sio TT, Paredes M, Uzair C. Neurological manifestation of colonic adenocarcinoma. Rare Tumors. 2012;4(2):98-100. https://doi.org/10.4081/rt.2012.e32

94. Rossor AM, Perry F, Botha A, et al. Opsoclonus myoclonus syndrome due to squamous cell carcinoma of the oesophagus. BMJ Case Reports. 2014. https://doi.org/10.1136/ bcr-2013-202849

95. Bataller L, Graus F, Saiz A, et al. Clinical outcome in adult onset idiopathic or paraneoplastic opsoclonus-myoclonus. Brain. 2001;124(2):437-43. https://doi.org/10.1093/ brain/124.2.437

96. Chao D, Chen W-C, Thirkill CE, et al. Paraneoplastic optic neuropathy and retinopathy associated with colon adenocarcinoma. Canadian Journal of Ophthalmology/Journal Canadien d'Ophtalmologie. 2013;48(5):e116-e20.

97. Rahimy E, Sarraf D. Paraneoplastic and non-paraneoplastic retinopathy and optic neuropathy: evaluation and management. Survey of Ophthalmology. 2013;58(5):430-58. https://doi.org/10.1016/j.survophthal.2012.09.001

98. Urai Y, Matsumoto K, Shimamura M, et al. Paraneoplastic necrotizing myelopathy in a patient with advanced esophageal cancer: an autopsied case report. Journal of the Neurological Sciences. 2009;280(1-2):113-7. https://doi. org/10.1016/j.jns.2009.02.324

99. Shimoda T, Koizumi W, Tanabe S, et al. Small-cell carcinoma of the esophagus associated with a paraneoplastic neurological syndrome: a case report documenting a complete response. Japanese Journal of Clinical Oncology. 2006;36(2):109-12. https://doi.org/10.1093/jjco/hyi241
100. Macdonell RA, Rich JM, Cros D, et al. The Lambert-Eaton myasthenic syndrome: a cause of delayed recovery from general anesthesia. Archives of Physical Medicine and Rehabilitation. 1992;73(1):98-100.

101.Pautas E, Cherin P, Wechsler B. Polymyositis as a paraneoplastic manifestation of rectal adenocarcinoma. The American Journal of Medicine. 1999;106(1):122-3.

102. Katzka DA, Farrugia G, Arora AS. Achalasia secondary to neoplasia: a disease with a changing differential diagnosis. Diseases of the Esophagus: officialjournal of the International Society for Diseases of the Esophagus. 2012;25(4):331-6. https://doi.org/10.1111/j.1442-2050.2011.01266.x

103. Taverna JA, Babiker HM, Yun S, et al. The great masquerader of malignancy: chronic intestinal pseudo-obstruction. Biomarker Research. 2014;2(1):23-8. https://doi. org/10.1186/s40364-014-0023-y

104. Kashyap P, Farrugia G. Enteric autoantibodies and gut motility disorders. Gastroenterol Clin North Am. 2008;37(2):397410. https://doi.org/10.1016/j.gtc.2008.02.005

105. Argyriou KN, Peters M, Ishtiaq J, et al. A rare case of paraneoplastic syndrome presented with severe gastroparesis due to ganglional loss. Case Reports in Medicine. 2012. https://doi.org/10.1155/2012/894837

106. Brown WR, Dee E. Dysphagia in a patient with recurrent smallcell lung cancer. Gastroenterology. 2013;144(1):34:252-3. https://doi.org/10.1053/j.gastro.2012.08.007

107.Ebert EC. Gastrointestinal and hepatic manifestations of systemic diseases. En: Feldman M, Friedman LS, Brandt LJ (editores). Sleisenger and Fordtran's gastrointestinal and liver disease: pathophysiology, diagnosis, management. Estados Unidos: Elsevier; 2016. pp. 579-616.

108.Donthireddy KR, Ailawadhi S, Nasser E, et al. Malignant gastroparesis: pathogenesis and management of an underrecognized disorder. J Supp Oncol. 2007;5(8):355-63. 